\title{
Imaging-based observations of low-latitude auroras during 2001-2004 at Nayoro, Japan
}

\author{
Hidehiko Suzuki ${ }^{*}$, Haruka Chino ${ }^{2}$, Yasuo Sano ${ }^{3}$, Akira Kadokura ${ }^{4,5}$, Mitsumu K Ejiri ${ }^{4,5}$ and Makoto Taguchi ${ }^{2}$
}

\begin{abstract}
Color images of six low-latitude auroral events observed using color digital cameras at Nayoro $\left(142.5^{\circ} \mathrm{E}, 44.4^{\circ} \mathrm{N}\right)$, Hokkaido, Japan, from 2001 to 2004, were analyzed to determine the events' locations and times of occurrence. Geographical azimuthal and elevation angles of the images' pixels were determined precisely by using the positions of the stars captured in the images. Horizontal regions covered by these auroral events were directly indicated by mapping the color images onto geographical maps and assuming that the emission layer's altitude is the lowest or highest value of a visible-level red aurora, as determined by the Ol $630.0 \mathrm{~nm}$ emission. The estimated geomagnetic latitudes and $L$ values of these low-latitude auroral events were in the 39-50 range and below $L<2.5$, respectively. This investigation indicates that four of the six auroral events were the same as those that were reported previously based on high-sensitivity optical observations at other sites on Hokkaido (Rikubetsu and Moshiri). Although the previous study is lacking information about the maximal brightness level of the red auroral events, the present investigation suggests that these four low-latitude auroral events reached the visible level. In addition, two new events were reported in this study. The present work provides essential information such as the morphology and appearance of visible auroras, which are extremely rare in mid- or low-latitude regions.
\end{abstract}

Keywords: Low-latitude aurora; Magnetosphere; Imaging observation; Color digital camera; Hokkaido

\section{Background}

Auroras that are observed from unusually lower latitude regions relative to the typical auroral zone (at $\pm 60-70^{\circ}$ of geomagnetic latitude) during large geomagnetic storms are termed low-latitude auroras. For example, visible auroras were observed at eastern Jamaica $\left(17.92^{\circ} \mathrm{N}\right.$, $\left.176.2^{\circ} \mathrm{W}\right)$ and at the Southern Pacific island of Samoa $\left(13.83^{\circ} \mathrm{S}, 171.75^{\circ} \mathrm{W}\right)$, at the geomagnetic latitudes of $30.4^{\circ}$ and $13.0^{\circ}$, respectively, during a great geomagnetic storm on May 14-15, 1921 (Silverman and Cliver 2001). Excluding the event at Samoa, it was concluded that the equator-ward extent of the aurora was between $30^{\circ}$ and $35^{\circ}$ of geomagnetic latitude after considering the consistency among many records of visual observations performed at various sites. A spectroscopic study has classified the emissions of low-latitude auroras into two types: 1) $\mathrm{N}_{2}^{+}$-the first negative band at dominant high vibrational states, and 2) the red OI $630.0 \mathrm{~nm}$ line dominant types (Tinsley et al. 1984). Since human eyes are more sensitive

\footnotetext{
* Correspondence: suzuhide@meiji.ac.jp

'Meiji University, Kawasaki, Kanagawa, Japan

Full list of author information is available at the end of the article
}

to red than to violet light, low-latitude auroras are visually characterized by a spectacular red color, reminiscent of the color of distant wild fires (Loomis 1861).

The Japanese archipelago is located between $20.4^{\circ} \mathrm{N}$ and $45.0^{\circ} \mathrm{N}$ and between $123^{\circ} \mathrm{E}$ and $154^{\circ} \mathrm{E}$ of geographical latitude and longitude, respectively. Even in the northernmost area of Japan, the geomagnetic latitude is only about $40^{\circ}$. Thus, auroras are quite unusual for Japan's population. However, several descriptions of visual observations of "red sky" events, which are regarded as low-latitude auroras, can be found in the historical literature. Nakazawa et al. (2004) summarized 16 old records of the low-latitude auroras described in the old chronicles and personal diaries written between 1150 and 1859. In this summary, several records of unusual sky conditions (red skies) observed from Tokyo and Kyoto were introduced, and it was concluded that these conditions likely preceded the low-latitude auroras.

More recently, quantitative observations of low-latitude auroras have been conducted in Japan. Miyaoka et al. (1990) reported a quantitative observation of a lowlatitude auroral event occurring on October 21, 1989, 
which was observed by using scanning photometers equipped with band pass filters for dominant auroral emission lines at the wavelengths of 427.8, 557.7, 630.0, and $668.3 \mathrm{~nm}$. Shiokawa et al. (2005) reported 20 low-latitude auroral events in Japan during the solar maximum period between 1999 and 2004. These researchers employed the optical mesosphere thermosphere imagers (OMTIs) system, consisting of a highly sensitive cooled CCD camera and photometers with narrow band pass filters for deducing the location, absolute intensity, and spatial distribution of low-latitude auroras (Shiokawa et al. 1999). Importantly, this study showed that invisible auroral events occurred more frequently ( 20 events in 6 years) than expected, compared with the past naked eye observations of visiblelevel auroras. This study also reported several events with brightness potentially reaching the "visible" level ( $>5 \mathrm{kR}$ at $630.0 \mathrm{~nm}$ ); however, there were no witnesses of these events because the observations were fully automated. This implies that even a familiar imaging device, such as a commercial digital camera, can be used for detecting low-latitude auroral events, if a fast lens and a long exposure are employed. In some recent studies, color digital cameras have already been applied to the scientific observations of auroras in the polar region (Sigernes et al. 2008; Kataoka et al. 2015). It is even possible to construct a network of automated digital cameras with a data logging system for monitoring low-latitude auroras in a wide area, at a low cost of running. Recently, Shiokawa et al. (2013) reported a simultaneous observation of a low-latitude aurora using satellites and ground-based optics at Rikubetsu, Japan. They showed the relationship between the location of the plasma pause and the ring current observed by the imager from magnetopause-to-aurora global exploration (IMAGE) satellite and the NOAA/POES-16 satellites during the low-latitude auroral event, and suggested a novel mechanism explaining the generation of energetic electrons responsible for the low-latitude aurora during the initial phase of the geomagnetic storm.

As this case indicates, it is obvious that the groundbased imaging technique is a valuable method for determining the spatial distributions of low-latitude auroras. Such information is essential for discussing the origin of the electrons responsible for the generation of lowlatitude auroras. In this study, we analyzed six color images of low-latitude visible-level auroral events observed at Nayoro (44.4 $4^{\circ}$ N), Hokkaido, Japan, from 2001 to 2004, by using color digital cameras. Four of these events occurred at the same time as the events reported by Shiokawa et al. (2005), while the other two events are herein reported for the first time. The geomagnetic latitudes and occurrence times of the geomagnetic storms for the six events are also discussed.

\section{Methods}

\section{Low-latitude auroral events captured by} color digital cameras

The dates and times of the low-latitude auroral events and details of the cameras used for acquiring the images are summarized in Table 1 . The images were acquired from 2001 by 2004, within $5 \mathrm{~km}$ of the Nayoro Astronomical Observatory, by the same staff member. The sky conditions were observed every day by the naked eye and auroral features were recognized when the northern part of the sky appeared abnormally red in the images. Excluding the event $\mathrm{A}$ in Table 1, all photographs were taken by using a commercial digital camera with a wide field-of-view lens. Event A was captured by using a film camera and converted to a digital image by using a film scanner.

Figure 1 shows the original images of the low-latitude auroras for all events (events A to F). The sky areas showing an unusually red color relative to the dark background sky are considered to be the locations of lowlatitude auroras. The red-color differences between the six events are considered to be caused by the white balance setting differences of the different shootings. Figure 2 shows the Dst index for the days with auroral events (data from the Dst index service of the World Data Center for Geomagnetism, Kyoto: http:// wdc.kugi.kyoto-u.ac.jp/). Thick solid lines show the times of the events in UT. It is noted that all events, excluding the event $\mathrm{B}$, occurred during the recovery phases of the corresponding geomagnetic storms.

\section{Image processing procedure}

Methods for inferring instrumental constants and coordinate systems for the different events, by using the images of stars, are described in this section. The basic premise of this calibration technique is not new, and was introduced at the beginning of the 20th century by Carl Størmer who pioneered an "imaging" study of auroras. A similar method has also been applied to the data from all-sky imaging camera networks covering North America (THEMIS project) (Mende et al. 2009), Finland and northern Scandinavia (MIRACLE project) (Syrjäsuo et al. 1998). In the present study, the image processing procedure for determining the azimuthal and elevation angles of the field-of-view corresponding to the pixels in the images consisted of the following four steps: (1) estimating the projection constant $A[\mathrm{rad} / \mathrm{pixel}]$ (see below for a definition), which depends on the imaging system (e.g., a lens and a CCD), (2) mapping the known stars in the image onto the spherical coordinates system, by using the estimated projection constant, (3) calculating a set of Euler angles $(\alpha, \beta, \gamma)$ for converting the spherical coordinates to the local horizontal coordinates at the 
Table 1 Details of the low-latitude auroral events and instrumental information

\begin{tabular}{|c|c|c|c|}
\hline Event & Date & $\begin{array}{l}\text { Time in UTC } \\
(\mathrm{LT}=\text { UTC }+9)\end{array}$ & Camera, lens, and settings \\
\hline \multirow[t]{6}{*}{ A } & \multirow[t]{6}{*}{ March 31, 2001} & \multirow[t]{6}{*}{$11: 23$} & Camera: Olympus OM-3 \\
\hline & & & $\begin{array}{l}\text { Film: FujiFilm Super G800 } \\
\text { (ISO800) }\end{array}$ \\
\hline & & & Lens: SIGMA 15 mm F2.8 \\
\hline & & & Settings: \\
\hline & & & F\#: 2.8 \\
\hline & & & Exposure: $60 \mathrm{~s}$ \\
\hline \multirow[t]{6}{*}{ B } & \multirow[t]{6}{*}{ October 29, 2003} & \multirow[t]{6}{*}{ 10:05 } & $\begin{array}{l}\text { Camera: FujiFilm FinePix } \\
\text { S2 pro }\end{array}$ \\
\hline & & & Sensitivity: ISO800 \\
\hline & & & Lens: SIGMA 15 mm F2.8 \\
\hline & & & Settings: \\
\hline & & & F\#: 2.8 \\
\hline & & & Exposure: $72 \mathrm{~s}$ \\
\hline \multirow[t]{6}{*}{ C } & \multirow[t]{6}{*}{ October 31, 2003} & \multirow[t]{6}{*}{$13: 42$} & $\begin{array}{l}\text { Camera: FujiFilm FinePix } \\
\text { S2 pro }\end{array}$ \\
\hline & & & Sensitivity: ISO800 \\
\hline & & & Lens: SIGMA 15 mm F2.8 \\
\hline & & & Settings: \\
\hline & & & F\#: 2.8 \\
\hline & & & Exposure: $92 \mathrm{~s}$ \\
\hline \multirow[t]{6}{*}{ D } & \multirow[t]{6}{*}{ November 08, 2004} & \multirow[t]{6}{*}{$8: 37$} & Camera: Nikon D70 \\
\hline & & & Sensitivity: ISO800 \\
\hline & & & Lens: SIGMA 15 mm F2.8 \\
\hline & & & Settings: \\
\hline & & & F\#: 2.8 \\
\hline & & & Exposure: $79 \mathrm{~s}$ \\
\hline \multirow[t]{6}{*}{ E } & \multirow[t]{6}{*}{ November 09, 2004} & \multirow[t]{6}{*}{ 13:12 } & Camera: Nikon D70 \\
\hline & & & Sensitivity: ISO800 \\
\hline & & & Lens: SIGMA 15 mm F2.8 \\
\hline & & & Settings: \\
\hline & & & F\#: 2.8 \\
\hline & & & Exposure: $133 \mathrm{~s}$ \\
\hline \multirow[t]{6}{*}{$\mathrm{F}$} & \multirow[t]{6}{*}{ November 10, 2004} & & Camera: Nikon D70 \\
\hline & & & Sensitivity: ISO800 \\
\hline & & & Lens: SIGMA 15 mm F2.8 \\
\hline & & & Settings: \\
\hline & & & F\#: 2.8 \\
\hline & & & Exposure: $84 \mathrm{~s}$ \\
\hline
\end{tabular}

observation time and location, and (4) determining the horizontal coordinates corresponding to the pixels.

First, a projection constant $A$ was determined by using the known stars detected in the image. The definition of
$A$ was $\theta=A R$, where $R$ is the distance from the center of the image to the point corresponding to the direction in the image in pixels, and $\theta$ is the angular distance between the center and an arbitrary direction in the field-of-view, expressed in radians. If the elevation and azimuthal angles of the field-of-view center, $\left(\lambda_{\mathrm{c}}, \phi_{\mathrm{c}}\right)$, are known precisely, the projection constant can be directly estimated by using spherical trigonometry, as follows:

$$
A=\frac{\cos ^{-1}\left\{\sin \lambda_{\mathrm{s}} \sin \lambda_{\mathrm{c}}+\cos \lambda_{\mathrm{s}} \cos \lambda_{\mathrm{c}} \cos \left(\phi_{\mathrm{c}}-\phi_{\mathrm{s}}\right)\right\}}{\sqrt{X_{\mathrm{s}}^{2}+Y_{\mathrm{s}}^{2}}}[\mathrm{rad} / \text { pixel }],
$$

where $\left(\lambda_{\mathrm{s}}, \phi_{\mathrm{s}}\right)$ are the star's horizontal coordinates and $\left(X_{\mathrm{s}}, Y_{\mathrm{s}}\right)$ are the coordinates of the star on the image, measured in pixels. In this coordinate system, the origin is the image's center, and the $\mathrm{X}$ and $\mathrm{Y}$ axes are the horizontal and vertical directions, respectively. If $\left(\lambda_{\mathrm{c}}, \phi_{\mathrm{c}}\right)$ are known, the estimation of the projection constant $A$ becomes straightforward. However, for the present cases in which the values of $\left(\lambda_{c}, \phi_{c}\right)$ are not known, the horizontal coordinates of at least two stars are required for determining the projection constant $A$. Given the set of horizontal coordinates $\left(\lambda_{\mathrm{s} 1}, \phi_{\mathrm{s} 1}\right)$ and $\left(\lambda_{\mathrm{s} 2}, \phi_{\mathrm{s} 2}\right)$ of two known stars at $\left(X_{\mathrm{s} 1}, Y_{\mathrm{s} 1}\right)$ and $\left(X_{\mathrm{s} 2}, Y_{\mathrm{s} 2}\right)$ in the image, the projection constant $A$ should satisfy the law of cosines in spherical trigonometry, as follows:

$$
\cos \Theta_{12}=\cos A r_{1 \mathrm{c}} \cos A r_{2 \mathrm{c}}+\sin A r_{1 \mathrm{c}} \sin A r_{2 \mathrm{c}} \cos \theta_{12},
$$

where

$$
\begin{aligned}
& \Theta_{12}=\cos ^{-1}\left\{\sin \lambda_{\mathrm{s} 1} \sin \lambda_{\mathrm{s} 2}+\cos \lambda_{\mathrm{s} 1} \cos \lambda_{\mathrm{s} 2} \cos \left(\phi_{\mathrm{s} 2}-\phi_{\mathrm{s} 1}\right)\right\} \\
& r_{1 \mathrm{c}}=\sqrt{X_{\mathrm{s} 1}^{2}+Y_{\mathrm{s} 1}^{2}} \\
& r_{2 \mathrm{c}}=\sqrt{X_{\mathrm{s} 2}^{2}+Y_{\mathrm{s} 2}^{2}} .
\end{aligned}
$$

Here, $\theta_{12}$ is the difference (in radians) between the angle components of $\left(X_{\mathrm{s} 1}, Y_{\mathrm{s} 1}\right)$ and $\left(X_{\mathrm{s} 2}, Y_{\mathrm{s} 2}\right)$ in polar coordinates. The definitions of these values in the image coordinate system are summarized in Fig. 3. Thus, the projection constant $A$ is obtained by numerically solving these relationships and positions of the two known stars. If there are $N(\geq 2)$ known stars in the image, ${ }_{N} C_{2}$ independent values of the projection constant can be deduced. Then, by averaging these independent values, a more precise value of the projection constant $(A)$ can be determined for the system. As a second step, the image coordinates of $N$ known stars $\left(\left(X_{\mathrm{si}}, Y_{\mathrm{si}}\right), i=1,2,3, \cdots, N\right.$ in pixels) are mapped onto an arbitrary spherical coordinates system $\left(r_{0 \mathrm{i}}, \lambda_{0 \mathrm{i}}, \phi_{0 \mathrm{i}}\right)$ using the projection constant $A$. During this process, only the angular distance between any two stars is important. Therefore, the radius and the origin of the coordinates are arbitrary, and $r_{0}$ is taken to be unity for convenience. As a third step, 

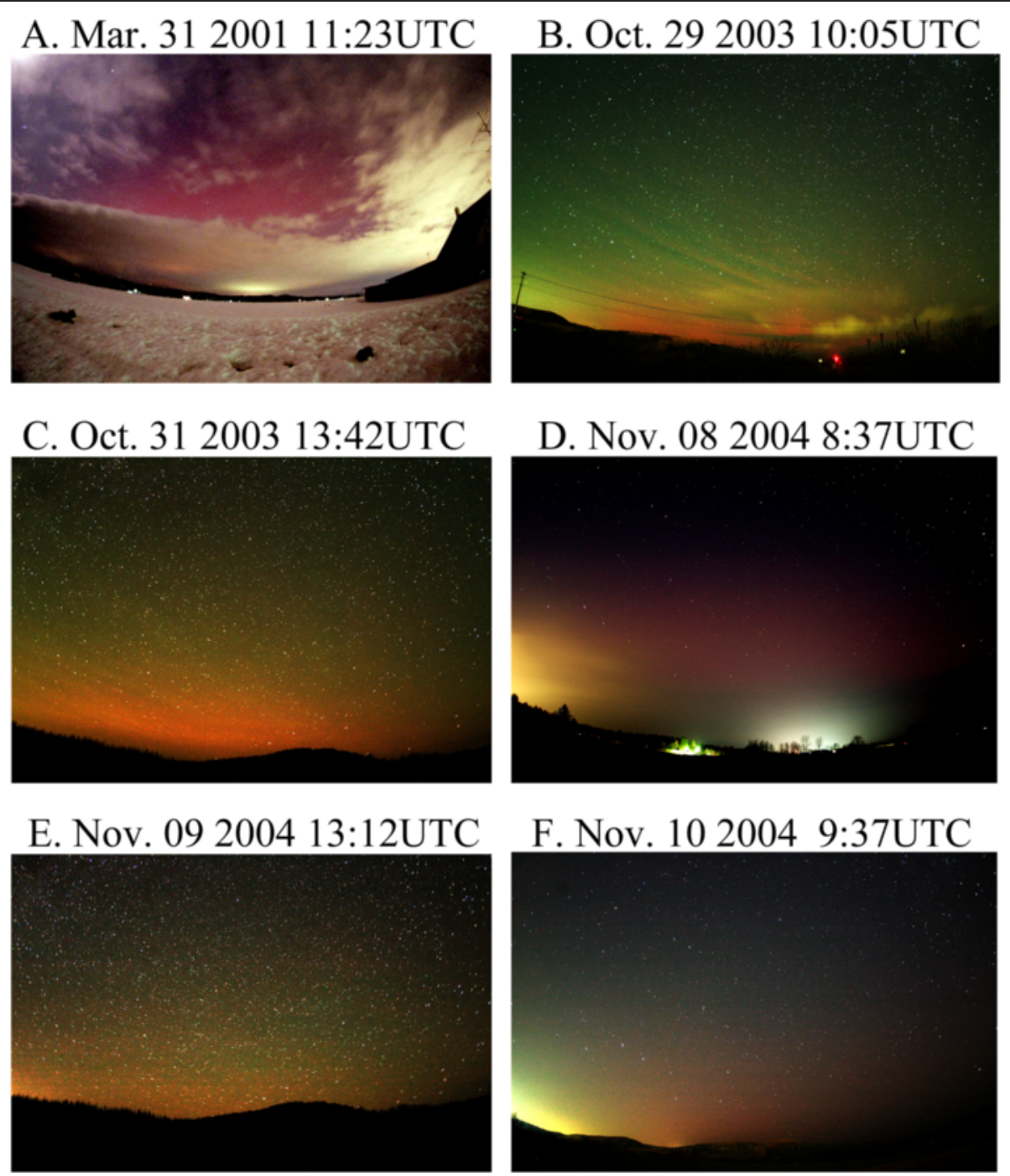

Fig. 1 Original images of the low-latitude auroras near Nayoro City $\left(44.4^{\circ} \mathrm{N}\right)$. a-f Detailed descriptions for each observation are listed in Table 1

an Euler rotation matrix, $E(\alpha, \beta, \gamma)$, is determined, that satisfies

$$
\left(\lambda_{\mathrm{si}}, \phi_{\mathrm{si}}\right)=E(\alpha, \beta, \gamma)\left(\lambda_{0 \mathrm{i}}, \phi_{0 \mathrm{i}}\right) i=1,2,3, \cdots, N
$$

where $\left(\lambda_{\mathrm{si}}, \phi_{\mathrm{si}}\right)$ are the local horizontal coordinates at the observation time of the known stars, while $N$ is the number of stars used for this calibration and it is required to be larger than three. Finally, the image coordinates of all pixels are converted to the local horizontal coordinate system by using the derived converting matrix $E(\alpha, \beta, \gamma)$. Figure 4 shows the result of this procedure for determining the local horizontal coordinate of the auroral image acquired on March 31, 2001 (Fig. 1a). In this case, five stars were used for determining the constant $A$ and the matrix $E(\alpha, \beta, \gamma)$. These stars are labeled by their intrinsic names in Fig. 4. The standard deviation between the derived coordinates of the stars and the known values obtained from an atlas was $0.3^{\circ}$. Therefore, the transformation precision in this case was within $\pm 0.3^{\circ}$, for the determined altitude and azimuthal angles.

\section{Results}

\section{Location of the low-latitude auroras}

In principle, if one auroral event is captured simultaneously at two or more locations, it should be possible to determine the mean altitude and horizontal distribution of the auroral layer by triangulation. Although the multiple-camera method cannot be applied in every case, it allows a powerful and robust identification of the emission layer of auroras in some circumstances (Mende et al. 2009). In this study, however, only the single-site images were available. Thus, the auroral 

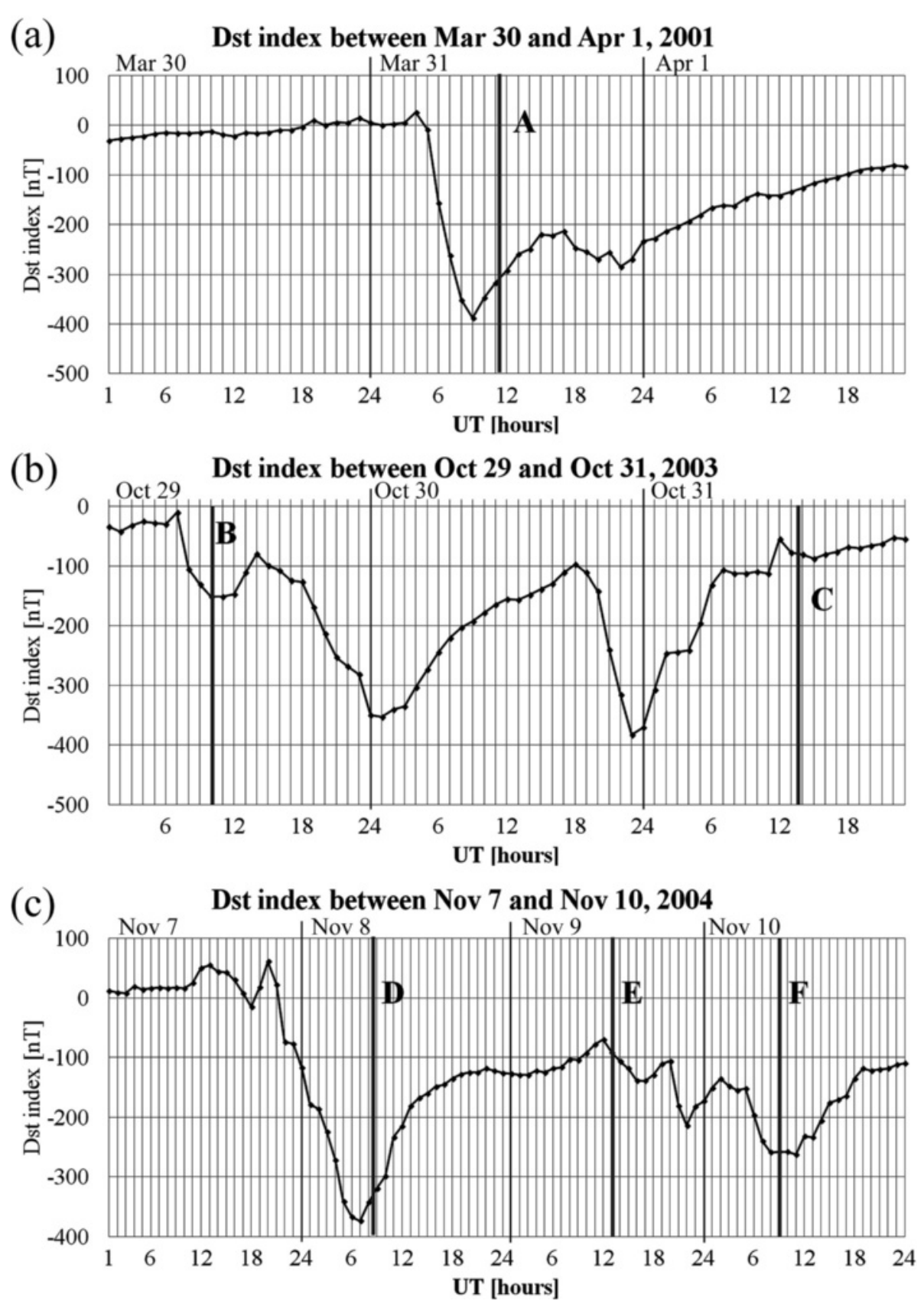

Fig. 2 a-c Dst index for the days on which the auroral events occurred. Thick solid lines show the events' time in UT (LT : UT+9h)

images were projected onto a geographical map by assuming the altitude of the corresponding emission layer. In this study, the altitudes of the auroral emission events were assumed to range from 150 to $400 \mathrm{~km}$. This assumption was based on the fact that all events featured red color, which is likely to represent the emission at $630.0 \mathrm{~nm}$ from atomic oxygen and reach the visible-level brightness. Although the $630.0 \mathrm{~nm}$ auroral emission was sometimes reported to occur above the altitude of $400 \mathrm{~km}$ (Okano and Kim 1987), the upper limit of the visible red auroral level is thought to be below $400 \mathrm{~km}$ (Shiokawa et al. 2005). In the present study, the color auroral images were projected onto maps by assuming the auroras altitudes to be 150 and $400 \mathrm{~km}$ for the possible lowest and highest cases, respectively. Figures 5, 6, 7, 8, 9, and 10 show the results of the projections of the auroral images (in color) onto the maps. Both the geographical and geomagnetic coordinates are shown on the maps. The corrected geomagnetic coordinate (CGM) system, based on the IGRF model, was 


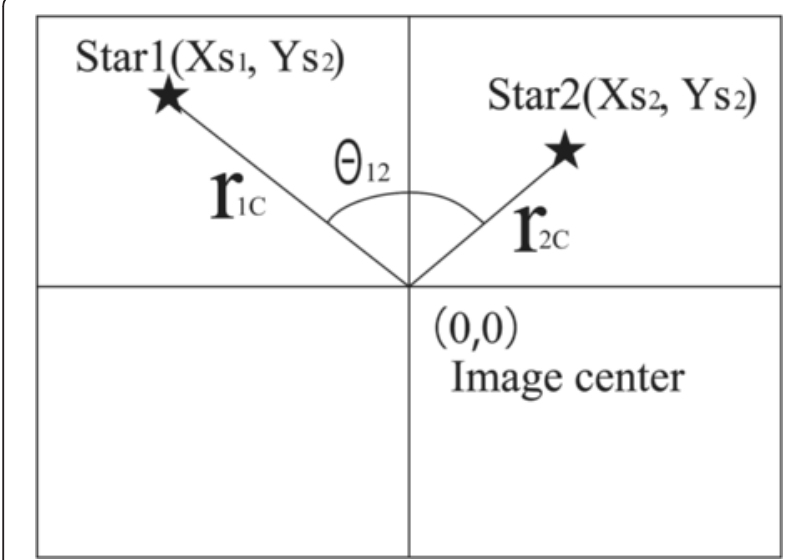

Fig. 3 Definition of the image coordinates. All distances are measured in pixels

used for calculating the geomagnetic latitudes and $L$ values for each year (Macmillan and Maus 2005). In Figs. 5, 6, 7, 8, 9, and 10, the white solid lines forming the trapezoidal-like shapes show the fields-of-view of the camera system, and the left and right panels show the cases in which the altitudes of 150 and $400 \mathrm{~km}$ were assumed, respectively. There are no supplemental data for determining whether the obtained auroral events are latitudinally extended as a layer structure such as airglow, or vertically distributed in a relatively narrow latitudinal range. Thus, only the lower latitude edges (i.e., the highest elevation angles) of the observed auroras were estimated from the projected images (Figs. 5, $6,7,8,9$, and 10). The bright, white structures visible in Figs. 5, 6, 8, and 10 are clouds illuminated by the light emanating from the city. There are also contaminations due to the scattered city light in the areas corresponding to the low elevation angles. In some cases, these non-auroral structures may impact the precise estimation of the longitudinal extent of auroras. However, their effect on the evaluation of the lower latitude edges of the auroras was minimal because this analysis only considered the images' areas corresponding to higher elevation angles. The latitude of the auroral event on March 31, 2001 (event A), was the lowest for all events. This event reveals the red feature of the aurora over the geographical latitudes around $45^{\circ} \mathrm{N}\left(48^{\circ} \mathrm{N}\right)$ when the altitude was assumed to be 150 $(400 \mathrm{~km})$. This estimated region (GLAT $45-48^{\circ} \mathrm{N}$ ) of the low-latitude aurora corresponds to the southern area of the Sakhalinskaya Island. Similarly, the lowest latitude edges of the other events were estimated in both geographical and geomagnetic coordinate systems. The results for these events are listed in Table 2. All of the events, excluding the event $\mathrm{B}$, occurred during the recovery phases of the corresponding storms. In addition, the estimated $L$ values for these events were below 2.4, even if the auroral altitudes were assumed to be $400 \mathrm{~km}$. For the six low-latitude auroral events, the lower edge values of the geomagnetic latitudes ranged from $38^{\circ} \mathrm{N}$ to

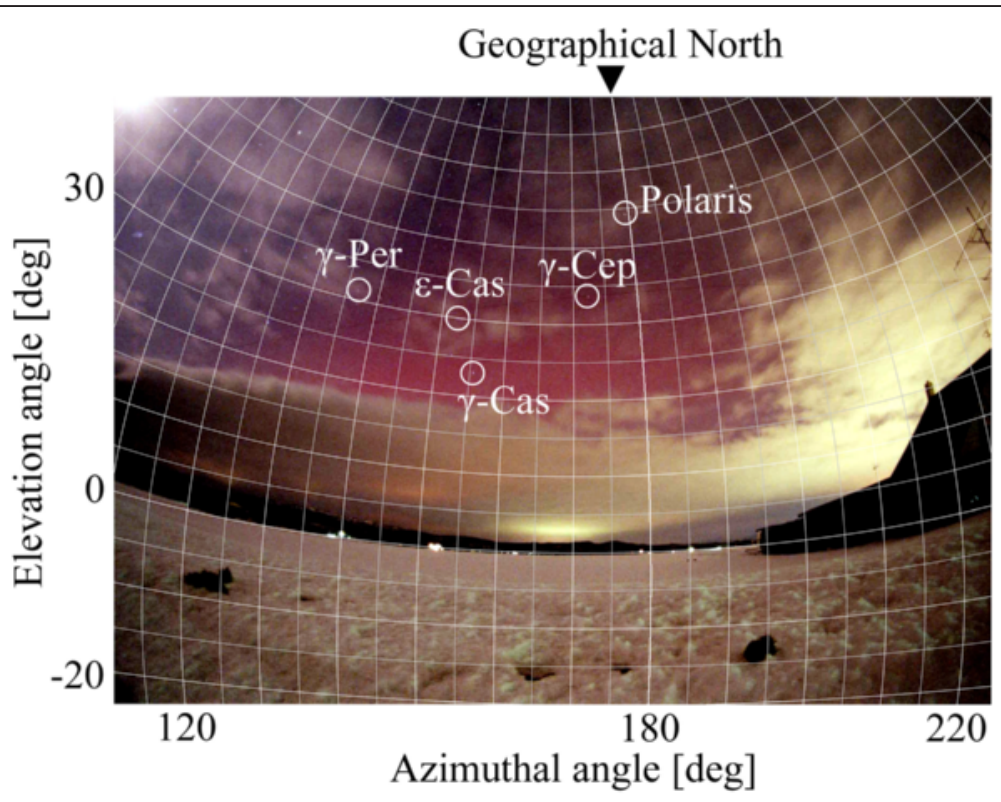

Fig. 4 Example of an aurora image with the horizontal coordinates determined by using the described procedure. The five stars used in this procedure are indicated by the circles and labeled by their intrinsic names. The original image of this figure is that of Fig. 1a (the event that occurred on March 31, 2001) 


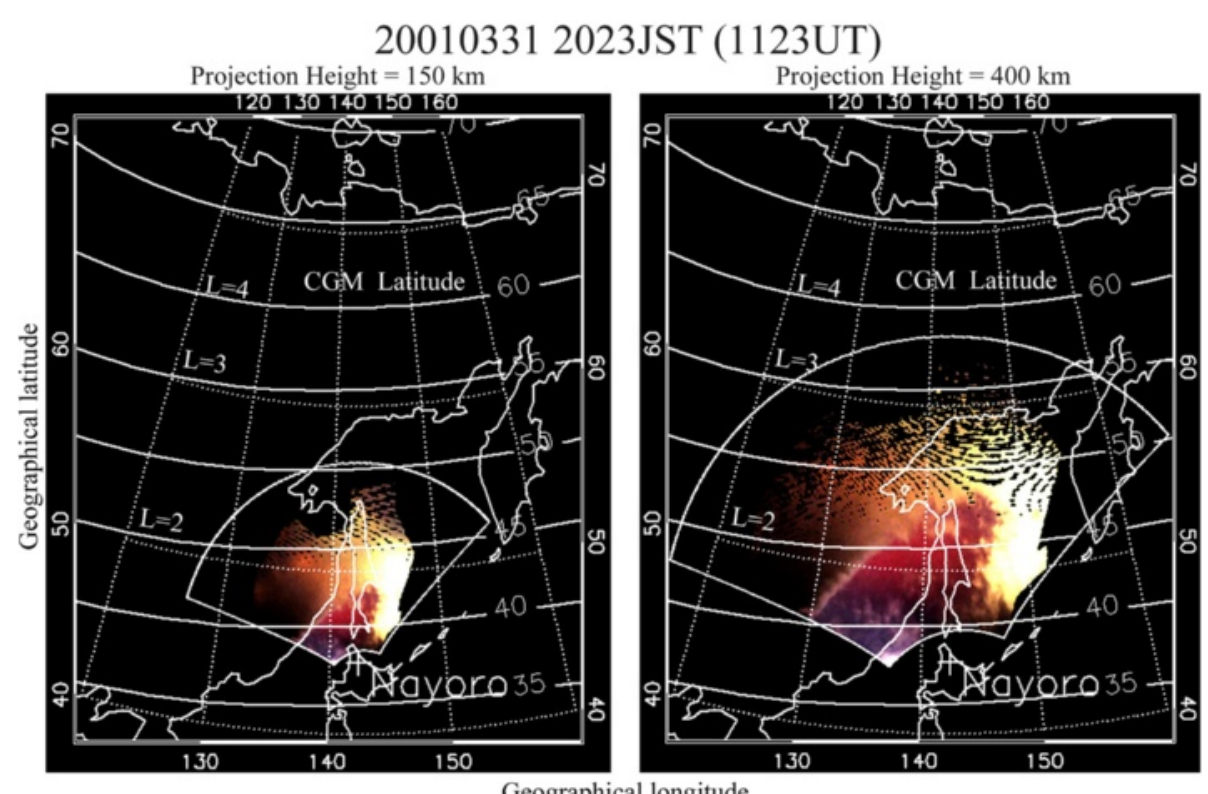

Fig. 5 The aurora observed on May 31, 2001. The image is projected onto a map by assuming the altitudes of $150 \mathrm{~km}$ (left panel) and $400 \mathrm{~km}$ (right panel), respectively. The enclosed solid line with a trapezoidal-like shape shows the field-of-view of the camera system. The dotted grid lines show the geographical longitude and latitude. Thick solid lines show the magnetic latitudes and the corresponding $L$ values. The location of Nayoro City is indicated with a plus symbol. Artificial objects (e.g., buildings and power lines), mountains, and structures below the horizon are masked with black color

$50^{\circ} \mathrm{N}$. The values of the OI $630.0 \mathrm{~nm}$ brightness determined by Shiokawa et al. (2005) are listed in Table 2 as the references for the coincident events (the events $\mathrm{A}$ to D). The data from the OMTIs system (Shiokawa et al. 1999) at Rikubetsu also shows brightening of the
$630.0 \mathrm{~nm}$ emission in the Northern sky during the same period as that of the event $F$. The enhancement reached $\sim 400 \mathrm{R}$ and then decreased to $\sim 100 \mathrm{R}$ (the typical airglow intensity) by 9:30 UT. This maximal level of intensity was likely to be underestimated because a

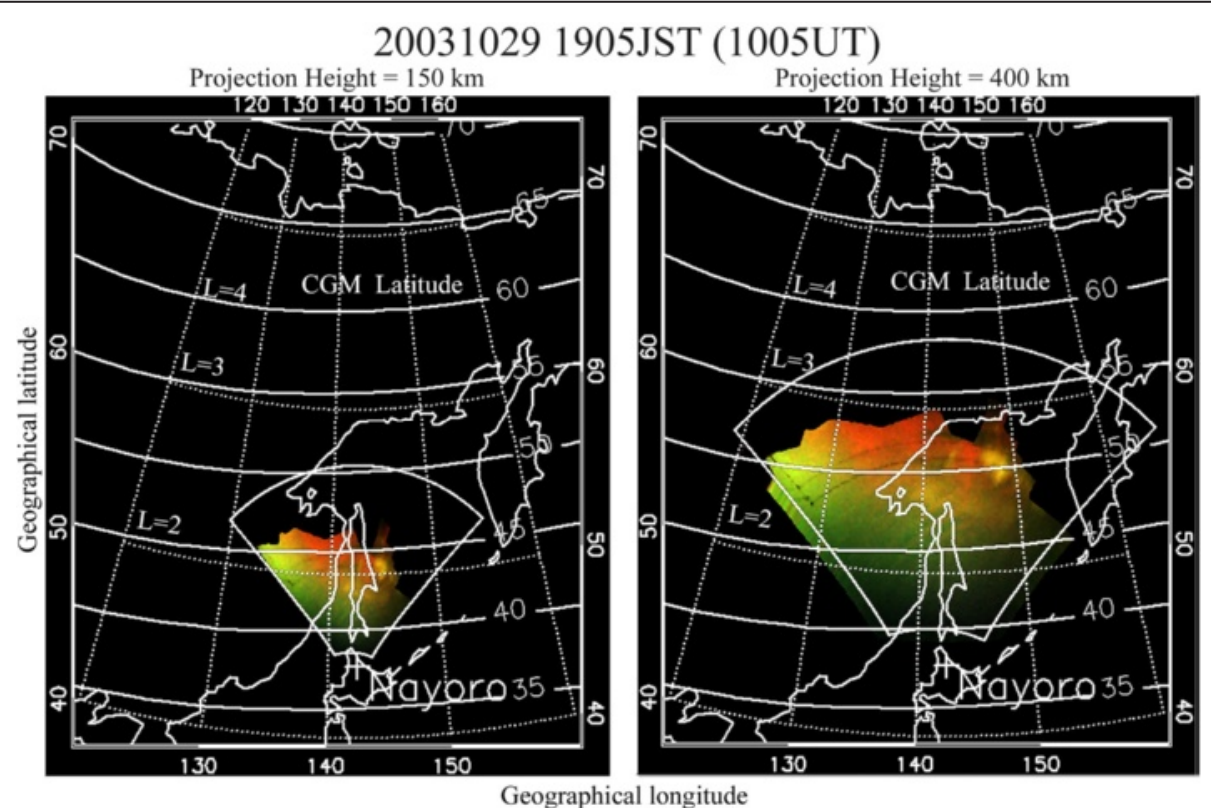

Fig. 6 The same as Fig. 5, but for the aurora observed on October 29, 2003 


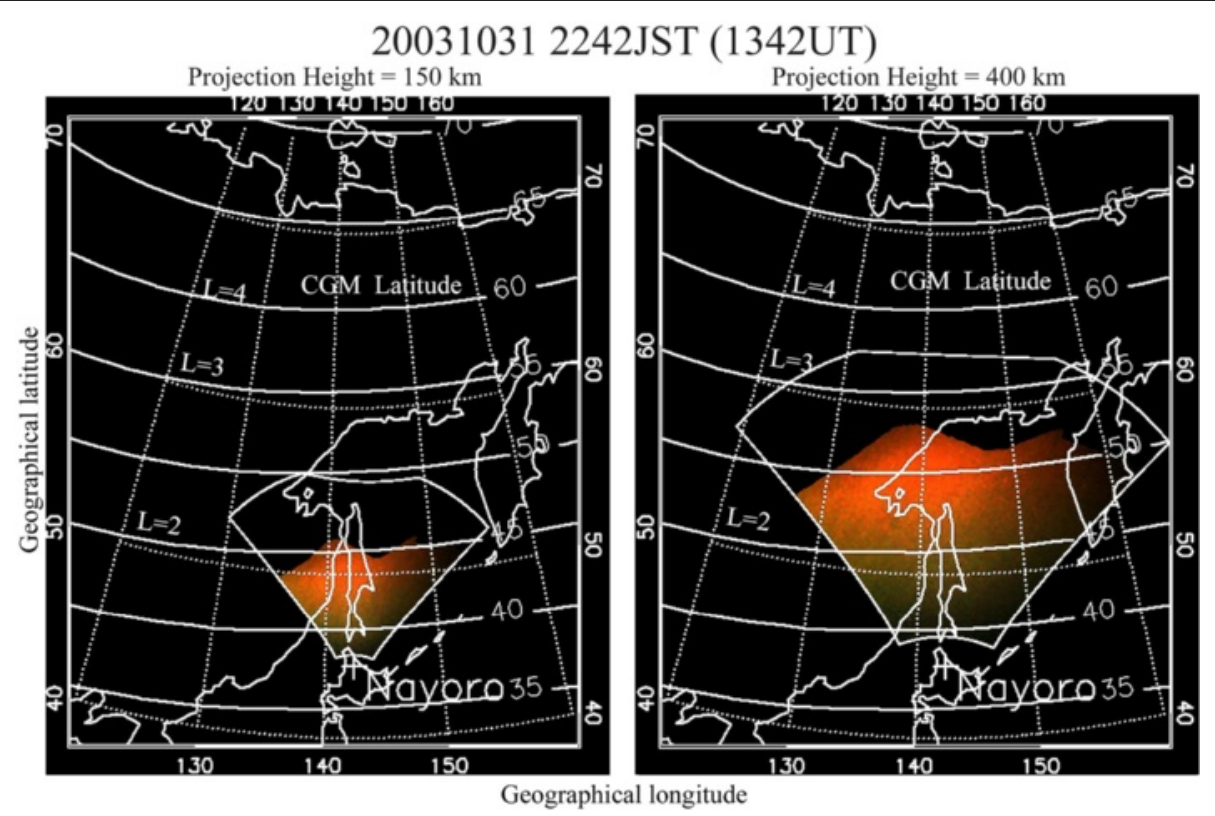

Fig. 7 The same as Fig. 5, but for the aurora observed on October 31, 2003

background level, monitored by another photometer of the OMTIs system, indicated a possibility of cloudy condition at that time (Shiokawa, private communication, 2015). Thus, there was additional evidence to support the low-latitude auroral events reported in the present study, excluding the event E. These facts are also noted in the last column of Table 2.

\section{Discussion}

It is possible to infer the absolute brightness of auroral events from color image data if spectral sensitivity data for the total optics (i.e., an objective lens and a CCD camera) obtained by pre-calibration are available (Sigernes et al. 2008). Unfortunately, no calibration data were available for the total optics used in the

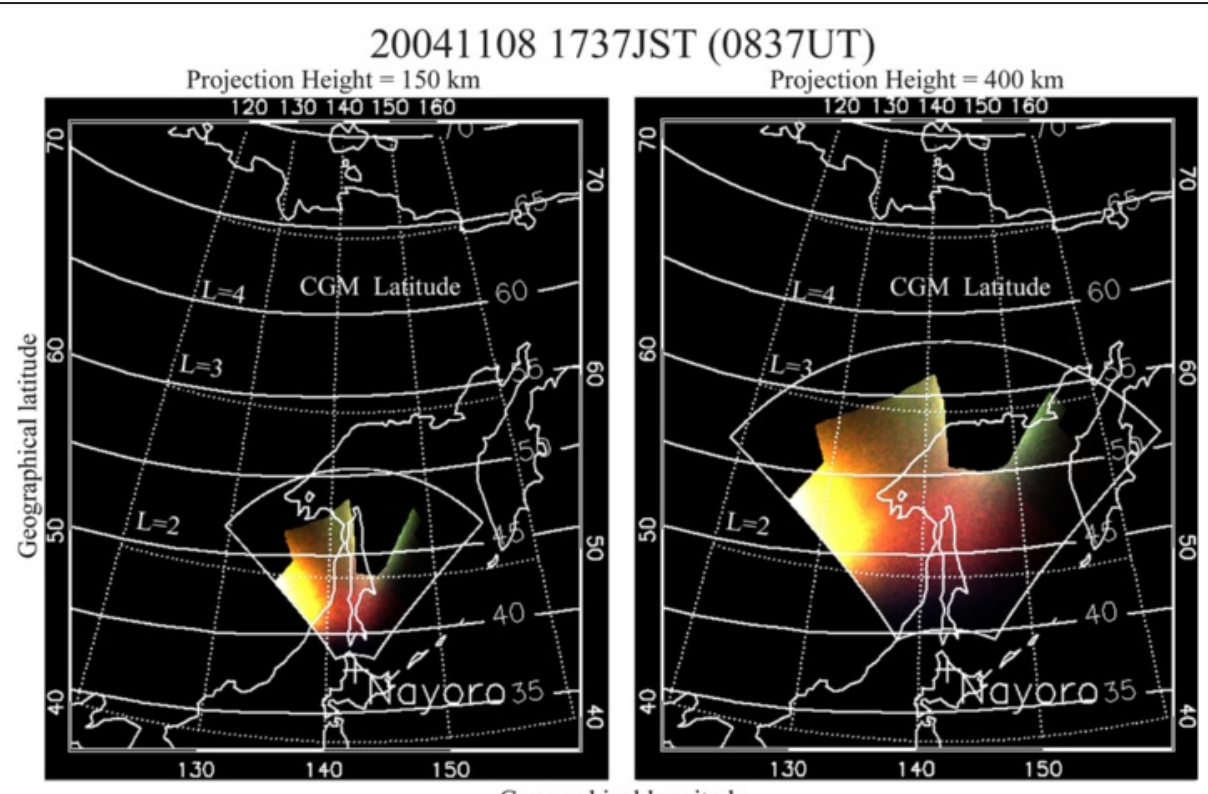

Geographical longitude

Fig. 8 The same as Fig. 5, but for the aurora observed on November 8, 2004 


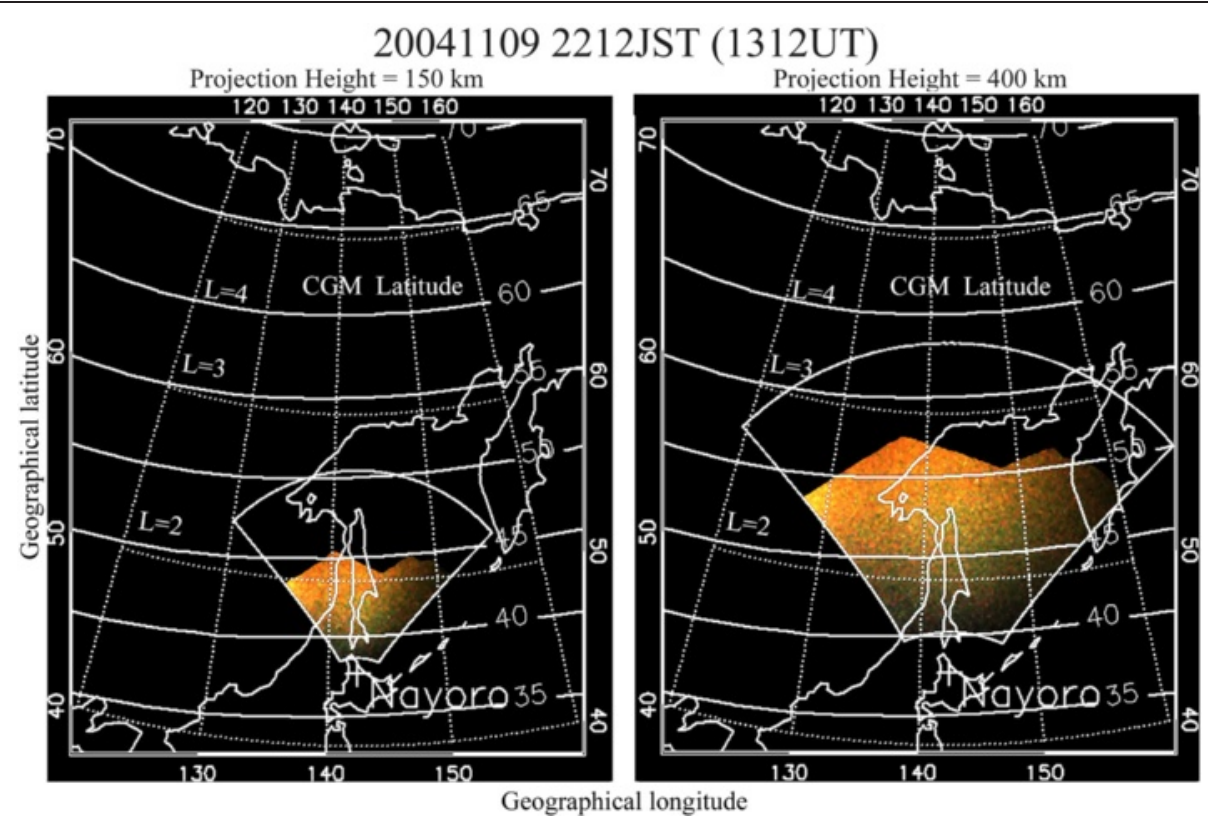

Fig. 9 The same as Fig. 5, but for the aurora observed on November 9, 2004

present study (see Table 1). Therefore, it was difficult to determine the exact intensity of the auroral events presented here. However, all of the events were considered to have brightness levels visible to the human eye, because non-special cameras were able to recognize an enhancement of the unusual red color over the northern sky. For one of the representative auroral lines, the so-called green line at $557.7 \mathrm{~nm}$, a brightness value of $1 \mathrm{kR}$ is thought to be at the visible level. This brightness is equivalent to that of the Milky Way in the dark sky. Human eyes are also more insensitive to the red light. According to the standard model of scotopic and photopic sensitivities of the human eye defined by international commission on illumination (CIE), the sensitivity at

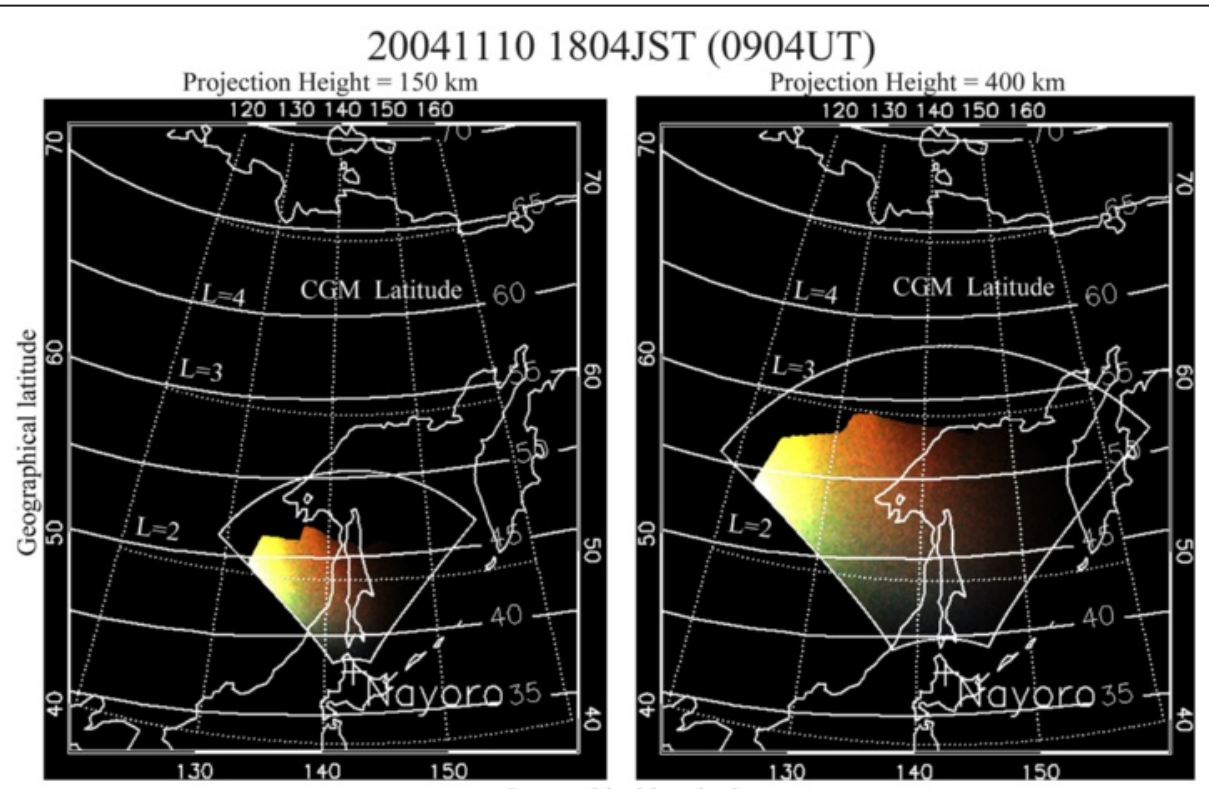

Geographical longitude

Fig. 10 The same as Fig. 5, but for the aurora observed on November 10, 2004 
Table 2 A summary of all events. The Ol 630.0nm brightness values reported by Shiokawa et al. (2005) are shown as the reference values

\begin{tabular}{|c|c|c|c|c|c|c|}
\hline Event & $\begin{array}{l}\text { Date and time in UTC } \\
{[\mathrm{LT}=\mathrm{UTC}+9 \mathrm{~h}]}\end{array}$ & Storm phase & $\begin{array}{l}\text { Storm min } \\
\text { Dst }[n T]\end{array}$ & $\begin{array}{l}\text { Low lat edge CGM } \\
\text { (GEO) [deg] }\end{array}$ & $\begin{array}{l}\text { Ol630 intensity reported by } \\
\text { Shiokawa et al. (2005) }\end{array}$ & $\begin{array}{l}\text { Support evidence } \\
\text { (see text) }\end{array}$ \\
\hline \multirow[t]{2}{*}{ A } & March 31, 2001/11:23 & Recovery & -383 & $38-41(45-48)$ & $>1.0$ kR (Rikubetsu) & Yes \\
\hline & & & & $1.6<L<1.8$ & & \\
\hline \multirow[t]{2}{*}{ B } & October 29, 2003/10:05 & Initial & -350 & $43-50(50-56)$ & $>2.2 \mathrm{kR}$ (Rikubetsu $\left.{ }^{\mathrm{a}}\right),>0.9 \mathrm{kR}$ (Moshiri) & Yes \\
\hline & & & & $1.9<L<2.4$ & & \\
\hline \multirow[t]{2}{*}{ C } & October 31, 2003/13:42 & Recovery & -383 & $41-46(48-52)$ & $>0.7$ kR (Rikubetsu), >4.0 kR (Moshiri) & Yes \\
\hline & & & & $1.8<L<2.0$ & & \\
\hline \multirow[t]{2}{*}{ D } & November 8, 2004/8:37 & Recovery & -374 & $40-43(46-50)$ & $>2.2$ kR (Rikubetsu) & Yes \\
\hline & & & & $1.7<L<1.9$ & & \\
\hline \multirow[t]{2}{*}{ E } & November 9, 2004/13:12 & Recovery & -374 & $41-47(48-53)$ & No reports & No \\
\hline & & & & $1.8<L<2.1$ & & \\
\hline \multirow[t]{2}{*}{$\mathrm{F}$} & November 10, 2004/9:04 & Recovery & -263 & $43-50(50-56)$ & No reports & Yes \\
\hline & & & & $1.9<L<2.4$ & & \\
\hline
\end{tabular}

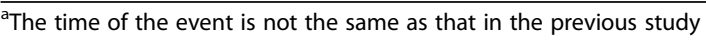

$630.0 \mathrm{~nm}$ is approximately $20 \%$ of that at $557.7 \mathrm{~nm}$ (Günther and Stiles 1982). This means that the auroral red line at $630.0 \mathrm{~nm}$ needs to reach a brightness value larger than $5 \mathrm{kR}$ in order to be visible. The events $\mathrm{A}$, $\mathrm{B}, \mathrm{C}$, and $\mathrm{D}$ are considered to be the same events reported by Shiokawa et al. (2005), because the estimated locations of the auroras were consistent with the results of these authors. The lower latitude edges of the six low-latitude auroral events ranged from $38^{\circ}$ to $50^{\circ}$ of geomagnetic latitude $(1.6<L<2.4)$. These results are consistent with those (MLAT $40-50^{\circ}$ ) estimated by Shiokawa et al. (2005). However, as cautioned, the brightness values of the $630.0 \mathrm{~nm}$ auroral emissions reported in their paper (last column of Table 2) were considered to be the lower limits due to the instrument saturation and presence of clouds during the observations. Our complimentary results suggest that the red auroral events reported by Shiokawa et al. (2005) in Northern Hokkaido, Japan on March 31, 2001, October 29 and 31, 2003, and November 8, 2004 reached the visible brightness level ( $\sim \mathrm{kR}$ at $630.0 \mathrm{~nm})$.

All of the events, excluding the event B, occurred during the recovery phases of the corresponding geomagnetic storms. This feature is consistent with that of the stable auroral red (SAR) arc (Rees and Akasofu 1963). In addition, the estimated $L$ values for these events were below 2.4, even if the auroral altitudes were assumed to be $400 \mathrm{~km}$.

\section{Conclusions}

Six low-latitude auroral events with visible brightness $(>5 \mathrm{kR}$ at $630.0 \mathrm{~nm}$ ), observed using color digital cameras at Nayoro, Hokkaido, Japan, from 2001 to 2004, were analyzed for investigating their locations and times of emergence. As a result of this analysis, four of the six auroral events were identified as being the same events reported by Shiokawa et al. (2005). Since no witnesses or visual reports were mentioned in their study, the present work provides novel evidence that these reported events reached the visible level. Furthermore, the two additional events were investigated for the first time in this study. Although the images used in this study were not originally acquired for a scientific purpose, information on the shootings (sites and times) and star images captured on them allow us to estimate the precise locations of the auroras. Using a careful image-processing-based analysis, the estimated geomagnetic latitudes and $L$ values of these lowlatitude auroral events ranged from $39^{\circ}$ to $50^{\circ}$ and were below $L<2.5$, respectively. These results are consistent with the previously reported optical observations at Rikubetsu and Moshiri (Hokkaido, Japan). This study demonstrates the capability of a commercial color digital camera, without any modification for scientific observations, to provide images that reveal the morphological characteristics of low-latitude auroras. However, a single auroral image is insufficient for discussing the mechanism of low-latitude auroras. In addition, the wavelength ambiguity in color images makes it difficult to distinguish faint auroral features from artifacts (e.g., city lights). Adding an optical filter tuned for an auroral line to a digital camera would greatly enhance the data's scientific value. The combination of a network observation of auroral displays via ground-based digital cameras and in-situ observations of precipitating particles via satellites can be a powerful tool 
for studying low-latitude auroras. A new camera system for automatic routine observations has been installed at the Nayoro Astronomical Observatory and has been in operation since June 2012. The use of this system and of the other instruments installed in northern Hokkaido is expected to reveal more detailed and unambiguous structures of low-latitude auroras.

\section{Competing interests}

The authors declare that they have no competing interests.

\section{Authors' contributions}

$\mathrm{HS}$ and $\mathrm{HC}$ performed the analysis and image processing of auroral images. YS contributed to the data collection. KA, MKE, and MT performed the technical research on the optical observation. All authors contributed to the manuscript preparation and had read and approved the final version of the manuscript.

\section{Acknowledgements}

Dst indexes are provided from service of the World Data Center for Geomagnetism, Kyoto (http://wdc.kugi.kyoto-u.ac.jp/). The authors greatly appreciate Prof. Kazuo Shiokawa for granting the permission to refer to the OMTIs data (http://stdb2.stelab.nagoya-u.ac.jp/omti/).

\section{Author details}

${ }^{1}$ Meiji University, Kawasaki, Kanagawa, Japan. ${ }^{2}$ Rikkyo University, Toshimaku, Tokyo, Japan. ${ }^{3}$ Nayoro Observatory, Nayoro, Hokkaido, Japan. ${ }^{4}$ National Institute of Polar Research, Tachikawa, Tokyo, Japan. ${ }^{5}$ SOKENDAI (The Graduate University for Advanced Studies), Tachikawa, Tokyo, Japan.

Received: 15 September 2014 Accepted: 20 June 2015

Published online: 04 July 2015

\section{References}

Günther W, Stiles WS (1982) Color Science: Concepts and Methods, Quantitative Data and Formulae 2ed. Wiley-Interscience, New York

Kataoka R, Fukuda Y, Miyoshi Y, Miyahara H, Itoya S, Ebihara Y, Hampton D, Dahlgren H, Whiter D, Ivchenko N (2015) Compound auroral micromorphology: ground-based high-speed imaging. Earth Planets Space 67:23

Loomis E (1861) On the great auroral exhibition of Aug. 28th to Sept. 4th, 1859, and on auroras generally-8th article. Am J Sci Ser 2 32:318-335

Macmillan S, Maus S (2005) International Geomagnetic Reference Field-the tenth generation. Earth Planets Space 57:1135-1140

Mende SB, Harris SE, Frey HU, Angelopoulos V, Russell CT, Donovan E, Jackel B, Greffen M, Peticolas LM (2009) The THEMIS array of ground-based observatories for the study of auroral substorms. In: Burch JL, Angelopoulos V (eds) The THEMIS Mission. Springer, New York

Miyaoka H, Hirasawa T, Yumoto K, Tanaka Y (1990) Low latitude aurorae on October 21, 1989. I. Proc Jpn Acad Ser B 66:47-51

Nakazawa Y, Okada T, Shiokawa K (2004) Understanding the "SEKKI" phenomena in Japanese historical literatures based on the modern science of low-latitude aurora. Earth Planets Space 56:e41-e44

Okano S, Kim JS (1987) Observations of a SAR-arc associated with an isolated magnetic substorm. Planet Space Sci 35(4):475-482

Rees MH, Akasofu SI (1963) On the association between subvisual red arcs and the Dst $(H)$ decrease. Planet Space Sci 11:105-107

Shiokawa K, Katoh Y, Satoh M, Ejiri MK, Ogawa T, Nakamura T, Tsuda T, Wiens RH (1999) Development of optical mesosphere thermosphere imagers (OMTI). Earth Planets Space 51:887-896

Shiokawa K, Ogawa T, Kamide Y (2005) Low-latitude auroras observed in Japan: 1999-2004. J Geophys Res. doi:10.1029/2004JA010706

Shiokawa K, Miyoshi Y, Brandt PC, Evans DS, Frey HU, Goldstein J, Yumoto K (2013) Ground and satellite observations of low-latitude red auroras at the initial phase of magnetic storms. J Geophys Res 118:1-15

Sigernes F, Holmes JM, Dyrland M, Lorentzen DA, Svenøe T, Heia K, Aso T, Chernouss S, Deehr CS (2008) Sensitivity calibration of digital colour cameras for auroral imaging. Opt Express 16(20):15623-15632

Silverman SM, Cliver EW (2001) Low-latitude auroras: the magnetic storm of 14-15 May 1921. J Atmos Sol Terr Phys 63:523-535
Syrjäsuo M, Pulkkinen Tl, Janhunen P, Viljanen A, Pellinen RJ, Kauristie K, Thomas C (1998) Observations of substorm electrodynamics using the MIRACLE network. In: Substorms-4 Vol. 238., p 111

Tinsley BA, Rohrbaugh RP, Rassoul H, Barker ES, Cochran EL, Cochran WD, Wills BJ, Wills DW, Slater D (1984) Spectral characteristics of two types of low latitude aurorae. Geophys Res Lett 11:572-575

\section{Submit your manuscript to a SpringerOpen ${ }^{\circ}$ journal and benefit from:}

- Convenient online submission

- Rigorous peer review

- Immediate publication on acceptance

- Open access: articles freely available online

- High visibility within the field

- Retaining the copyright to your article

Submit your next manuscript at $>$ springeropen.com 